\title{
A dearth of new drugs
}

THE Californian court case in which Mrs Betty Mekdeci is trying to establish that Bendectin, an anti-nausea drug manufactured by Richardson Merrell, was responsible for the deformities with which her son was born, can hardly have come at a worse time for those who thought they could at last see some light at the end of the tunnel of regulations in which the pharmaceutical industry has found itself since the thalidomide tragedy of 1961 . Whatever the outcome of the case against Bendectin the blaze of publicity surrounding it is bound to make this a less than opportune moment for the political turn-about on regulations that seemed to be imminent, at least in the UK. Therefore it is important that the Bendectin case is used to illuminate rather than to obscure the arguments for and against relaxing regulations.

The pharmaceutical industry is prone to claim that were the regulations of the American Food and Drugs Administration to apply worldwide, no new drug would ever reach the market. Although that is hyperbole, it is true that regulations are more restrictive in the US than even in the UK which has the stiffest regulations in the European Economic Community. It is also true that the figures underlying the claims are dramatic. Compared to 20 years ago, it now takes about three times as long from the discovery to the marketing of a new drug. The demands for drug testing before marketing have risen enormously, some would say 100 -fold. The number of new drugs that reach the market each year has been halved. The cost of developing a successful drug now varies between $£ 3-5$ million. For every drug that reaches the public, several will have failed at the stage of clinical trials and many hundreds will have fallen by the wayside at an earlier stage.

Not too many tears need be shed in response to these facts. Drug testing by the industry used to be inadequate in both quantity and quality. In the immediate aftermath of thalidomide, better testing was either adopted by or forced upon the industry. But instances of inadequate testing continued to come to light thereafter and even if those instances were the whole, rather than the tip, of an iceberg, they provided some justification for the increasing stringency with which the whole industry became regulated. There has also been justification for the mandatory introduction of new and more sensitive methods of testing whatever the costs to industry.

Without a doubt the new drugs which now reach the public are safer than they used to be. The fact that there are fewer of them not only reflects the earlier detection and removal of hazardous drugs but also the growing and justifiable bias by regulators against "me-too" drugs, which ape the successful product of a rival, and in favour of truely innovative products.

On the other hand, regulations have had an irresistible tendency to breed further regulations because, faced with the possibility that lives are at stake, any regulatory body will understandably play safe. If a better, or even just a supplementary, test can be added to those already in force, it is safest to insist that it be carried out. Would it not be better to ask for the drug to be tested in an additional species? Why not replace a three month drug dosing period by one of a life time; and then why not insist on testing for any effects on the generation-or two?

By playing safe, the regulators are protecting themselves in the event of any unforseen tragedy as well as protecting the public. It is, however, possible to be over-protective towards the public. Regulations desgined to keep out the bad can also keep out, or at least hold up, the introduction of the good. That is what the pharmaceutical industry claims has happened to an unreasonable extent.

Much of their venom is directed against the bureaucrats. Why, they ask, does it take months for the UK Committee on Safety of Medicines to decide whether or not to grant permission for a clinical trial and up to a year for approval of a marketing licence after the clinical trial has been completed? (To which a partial answer is that it takes a long time to sift through the amount of evidence that is currently demanded and even longer when the evidence is inadequate or badly presented). More fundamentally, the industry and much of the medical profession, argue that, as a way of testing for hazards, animal testing and even clinical trials have limitations which are not adequately recognised. As a result too much time and effort, not to mention money, is devoted to trying to avoid what is unavoidable at that stage.

Animal tests will never provide a complete guide to human reactions to a drug and a clinical trial can never be on scale that is sufficient to detect side reactions of low incidence. It is argued that the path of a new drug both up to and through the clinical trial stage should be made easier. In return more attention should be paid than at present to the post-marketing stage. In other words the public should opt for taking more risks because of the greater benefits that such a decision would bring, on balance.

The general line of argument in favour of relaxing regulations is persuasive, but should only be met with a cautious practical response. There may be a case for cutting back on animal testing but if so, it is only on quantity in a limited number of respects and not at all on quality. There probably is a case for allowing and encouraging regulatory bodies to give a rapid, provisional goahead for companies to mount a clinical trial or even to market a new drug on the basis of a summary of the evidence before it is examined in full. But that procedure should be reserved for really innovative drugs and should not remove either the obligation for the company to provide the full evidence or for the regulators to examine it and, if necessary, to withdraw their provisional permission.

Finally, better ways will have to be devised for the monitoring of drugs once they are in full scale use. Although this is widely admitted in principle, there is little doubt that it will be resisted in practice, not least because it is likely to involve a cumbersome bureaucratic mechanism. However, had an adequate monitoring system already been in operation, we would surely have been spared, in one way or another, the need for the dramatic and emotional court room drama that is currently bringing anguish to the many women who took Bendectin early in their present pregnancy. 